VEGA, F.V.A.; BOVI, M.L.A.; BERTON, R.S.; GODOY JÚNIOR, G.; CEMBRANELLI, M.A.R. Aplicação de biossólido na implantação da cultura da pupunheira. Horticultura Brasileira, Brasília, v.22, n.1, p. 131-135, jan-mar 2004.

\title{
Aplicação de biossólido na implantação da cultura da pupunheira
}

\author{
Fernando Vinicio A. Vega; Marilene L.A. Bovi; Ronaldo Severiano Berton; Gentil Godoy Junior; \\ Matheus de A.R. Cembranelli \\ Instituto Agronômico, C. Postal 28, 13001-970 Campinas-SP; E-mail: fernandoarmas@yahoo.com.br
}

\section{RESUMO}

Avaliaram-se os efeitos de doses de biossólido aplicadas no sulco de plantio sobre a produção de fitomassa aérea de pupunheiras durante o primeiro ano do cultivo. $\mathrm{O}$ experimento foi instalado em Ubatuba (SP), tendo sido estudado quatro doses de lodo de esgoto (equivalentes a $0 ; 100 ; 200$ e $400 \mathrm{~kg} \mathrm{ha}^{-1}$ de $\mathrm{N}$ ), em esquema de blocos ao acaso, com seis repetições e quatro tratamentos. Foram utilizadas mudas com 10 meses de idade e densidade de plantio de 5.000 plantas ha ${ }^{-1}$. As respostas da planta às doses de biossólido foram avaliadas mensalmente, por meio de alguns caracteres diretamente relacionados ao crescimento e à produção de palmito. Com base na altura da planta foi estimado o acúmulo periódico da fitomassa aérea fresca da haste principal, ao longo do tempo. Houve diferença estatística a partir do $5^{\circ}$ mês de plantio para as diferentes doses, tempo em que a planta se adaptou ao campo e em que os nutrientes do biossólido começaram a ser assimilados. A resposta positiva no acúmulo de fitomassa aérea da pupunheira ao aumento de doses de biossólido antecipou o tempo para a primeira colheita na dose mais elevada, com $15 \%$ de plantas prontas para corte já aos 12 meses após a implantação da cultura. Houve também aumento no número de perfilhos por planta e na porcentagem de plantas perfilhadas em função das doses. Um ano após a aplicação de biossólido, pupunheiras da maior dose tinham, em média, cerca de $27 \mathrm{tha}^{-1}$ de fitomassa aérea total (base fresca), 3,3 perfilhos por planta e $77 \%$ de plantas perfilhadas.

Palavras-chave: Bactris gasipaes, lodo de esgoto, crescimento, palmito, pupunha.

\section{ABSTRACT \\ Sewage sludge application on peach palm (Bactris gasipaes Kunth)}

The effects of four doses of sewage sludge, applied in the planting furrow, on the aboveground biomass production of peach palm during the first year were evaluated. The experiment was carried out in Ubatuba, São Paulo State, Brazil, in field conditions. Four doses of biosolid (equivalent to $0 ; 100 ; 200$ and $400 \mathrm{~kg} \mathrm{ha}^{-1}$ of N) were studied in a complete block experimental design, with six replications. Tenmonth old seedlings from Putumayo landrace were utilized, in a planting density of 5,000 plants ha ${ }^{-1}$. Plant responses to biosolid doses were evaluated every month, by means of some traits directly correlated to peach palm growth and yield. Aboveground biomass (fresh weight base) accumulation was estimated, based on plant height. Statistical differences among doses were detected five months after planting, probably due to plant acclimation and nutrient assimilation. Anticipation of heart-of-palm harvesting could be detected, with $15 \%$ of plants ready to be harvested when treated with the dose of $400 \mathrm{~kg} \mathrm{ha}^{-1}$ of N. An increase occurred in the number of offshoots per plant and in the percentage of suckered plants per plot as a function of biosolid doses. One year after sludge application, in the maximum response treatment $\left(400 \mathrm{~kg} \mathrm{ha}^{-1}\right.$ of N), was obtained 27 ton $\mathrm{ha}^{-1}$ of aboveground biomass, 3.3 offshoots per plant and $77 \%$ of palms with offshoots were obtained.

Keywords: Bactris gasipaes, aboveground biomass, growth, offshoots, palmito, pejibaye.

\section{(Recebido para publicação em 06 de maio de 2003 e aceito em 17 de novembro de 2003)}

$\mathrm{O}$ cultivo da pupunheira (Bactris gasipaes Kunth.) para produção de palmito vem se expandindo no Brasil desde 1990, devido a uma série de vantagens quando comparado ao das espécies tradicionalmente utilizadas para essa atividade. A pupunheira é a mais precoce de todas as palmeiras atualmente em uso para a produção de palmito. A formação de mudas é simples e rápida (6 a 8 meses), levando em torno de 18 a 24 meses do plantio no campo à primeira colheita (Bovi, 1998).

Um crescimento acelerado é fundamental para o uso da pupunheira para a produção de palmito. Pelas características próprias do cultivo, com colheitas freqüentes e escalonadas em função do desenvolvimento das hastes, as plantas apresentamse em permanente estádio vegetativo, e a velocidade com que a fitomassa inicial se acumula e é reposta novamente após cada colheita, torna-se um indicador da produtividade e da vida econômica do cultivo (Clement e Bovi, 2000).

No entanto, a pupunheira é exigente em propriedades físicas do solo (Jorge e Bovi, 1994) e extrai grande quantidade de nutrientes do mesmo (Bovi e Cantarella, 1996; Falcão et al., 1998; Ares et al., 2002). A máxima produtividade é obtida somente com uso adequado de adubação (Bovi et al., 2002; Schroth et al., 2002).

Embora precoce em relação a outras palmeiras, reconhece-se que o crescimento e o desenvolvimento da pupunheira dependem basicamente das condições hídricas da área de cultivo (Bassoi et al., 1999; Ramos, 2002; Ra- mos et al., 2002) e das características físicas e da fertilidade do solo. Dessa forma, uma boa adubação inicial, feita ainda no sulco de plantio, é determinante para o crescimento da planta, contribuindo também para abreviar o tempo necessário para a primeira colheita (Bovi et al., 2000).

Várias fontes de matéria orgânica vêm sendo usadas na agricultura, como esterco de curral, composto de lixo, resíduos vegetais, entre outros. Ultimamente, atenção tem sido dada ao uso agrícola do biossólido. Resultados de pesquisa com biossólido em agricultura indicam que ele possui todos os nutrientes exigidos pelas plantas, e que seu emprego é altamente recomendável em milho, café, cana-de-açúcar, citros, espécies florestais e outras plantas pere- 
nes, devido aos altos teores de matéria orgânica (40-60\%), nitrogênio (4\%), fósforo ( $2 \%)$, e micronutrientes em geral. Atua também como condicionador do solo, melhorando as características físicas, agindo ainda em processos químicos e biológicos (Silva et al., 1998; Melo e Marques, 2000; Oliveira, 2000).

Este trabalho teve como objetivo avaliar os efeitos de quatro doses crescentes de biossólido, aplicadas no sulco de plantio, sobre a produção de fitomassa aérea de pupunheiras durante o primeiro ano do cultivo.

\section{MATERIAL E MÉTODOS}

$\mathrm{O}$ experimento foi instalado a campo, em Ubatuba (SP) $\left(23^{\circ} 27^{\prime} \mathrm{S}\right.$, $45^{\circ} 04^{\prime} \mathrm{W}$, a $6 \mathrm{~m}$ de altitude). O clima da região é "Cfa", pela classificação de Köppen, tropical quente e úmido, com pluviosidade anual normal de $2841 \mathrm{~mm}$, evapotranspiração potencial normal de $992 \mathrm{~mm}$, excedente normal de $1849 \mathrm{~mm}$, temperatura média anual de $20,8^{\circ} \mathrm{C}$ e déficit hídrico nulo.

O solo, próprio da área agricultável da região, é classificado como Aluvial álico (Udifluvent), com boa drenagem. É arenoso, com a composição granulométrica na profundidade de 0 $15 \mathrm{~cm}: 100 \mathrm{~g} \mathrm{~kg}^{-1}$ de argila, $140 \mathrm{~g} \mathrm{~kg}^{-1}$ de silte, $130 \mathrm{~g} \mathrm{~kg}^{-1}$ de areia fina e $630 \mathrm{~g}$ $\mathrm{kg}^{-1}$ de areia grossa. A maiores profundidades há progressiva diminuição na porcentagem de areia grossa e aumento da areia fina. A porosidade total na profundidade de $0-20 \mathrm{~cm}$ é de $49,97 \%$, sendo constituída por $29,65 \%$ de macroporos e $20,32 \%$ de microporos. A densidade global do solo está em torno de 1,05 $\mathrm{g} \mathrm{cm}^{-3}$ (Vega, 2003).

Devido à baixa saturação por bases $(21,3 \%)$ do solo foi feita aplicação de calcário dolomítico $\left(7 \mathrm{tha}^{-1}\right)$ de forma a elevar a saturação teórica por bases a $60 \%$. Após calagem, o solo apresentou as características químicas: $\mathrm{pH}_{\mathrm{CaCl} 2} 5,4$; MO 22,18 $\mathrm{g} \mathrm{dm}^{-3} ; \mathrm{P}_{\text {resina }} 7,94 \mathrm{mg} \mathrm{dm}^{-3}$; 1,$60 ; 19,85 ; 8,88 ; 36,44 \mathrm{mmol}_{\mathrm{c}} \mathrm{dm}^{-3}$, respectivamente de $\mathrm{K}, \mathrm{Ca}, \mathrm{Mg}$ e $\mathrm{H}+\mathrm{Al}$; 27,$15 ; 1,46 ; 0,25 ; 0,24 ; 0,17 ; 0,03 ; 0,03$ e $0,11 \mathrm{mg} \mathrm{dm}^{-3}$ respectivamente de $\mathrm{Fe}$, $\mathrm{Mn}, \mathrm{Cu}, \mathrm{Zn}, \mathrm{B}, \mathrm{Cd}, \mathrm{Cr}$ e Ni; V 47,5\%.

Foram avaliadas quatro doses de biossólido, em esquema de blocos ao acaso, com seis repetições (blocos), quatro tratamentos, 36 plantas por unidade experimental, sendo as 16 centrais as plantas úteis. Foram utilizadas bordaduras duplas ao redor de toda a área experimental. Utilizaram-se plantas de pupunheiras sem espinhos (inermes) da raça Putumayo, com 10 meses de idade. Adotou-se a densidade de plantio de 5.000 plantas ha-1 ${ }^{-1}$ a uma distância de 1 $\mathrm{m}$ entre plantas e $2 \mathrm{~m}$ entre linhas.

As doses empregadas foram calculadas levando-se em consideração as recomendações médias para o cultivo (200 $\mathrm{kg} \mathrm{N} \mathrm{ha}^{-1}$ ), preconizadas pelo IAC (Bovi e Cantarella, 1996), a composição química média do lodo da Estação de Tratamento de Esgoto de Bertioga (com 40,1 $\mathrm{g} \mathrm{kg}^{-1}$ de $\mathrm{N}_{\mathrm{kj}}, 4,60 \mathrm{~g} \mathrm{~kg}^{-1}$ de $\mathrm{N}_{\mathrm{NH} 4}$ e 48,9 $\mathrm{mg} \mathrm{kg}^{-1}$ de $\mathrm{N}_{\mathrm{NO} 3+\mathrm{NO} 2}$ na matéria seca) e fórmulas descritas por Tsutiya (2001). Dessa forma, resultaram em 0; 38; 76 e $152 \mathrm{t} \mathrm{ha}^{-1}$ de biossólido fresco $(79,7 \% \mathrm{de}$ umidade), equivalentes a $0 ; 100 ; 200 \mathrm{e}$ $400 \mathrm{~kg}$ de $\mathrm{N}$ por hectare.

Os tratamentos foram aplicados de uma única vez no sulco de plantio, adicionando-se $15 \mathrm{~g}$ por planta de cloreto de potássio como fonte de $\mathrm{K}_{2} \mathrm{O}$. Foram feitas adubações complementares com $15 \mathrm{~g}$ de cloreto de potássio e 2,4 de bórax por planta, em três datas ( 3 e 9 meses após plantio), com o objetivo de corrigir deficiências. Maiores informações sobre o cálculo de doses e instalação do experimento podem ser encontradas em Vega (2003).

As respostas da planta às doses de biossólido foram avaliadas mensalmente, por meio da altura da haste principal, medida do solo até a inserção da folha+1. Com base nessa variável foi estimado o acúmulo periódico da fitomassa aérea fresca da haste principal, ao longo do tempo. Isso foi feito por meio de equação $y=a x^{b}$ cujos parâmetros foram estimados por Vega (2003). Como a produção de palmito é avaliada pela massa fresca, optou-se por calcular as respostas às doses de biossólido na mesma base.

As medidas foram complementadas com a avaliação do número e da altura dos perfilhos por planta útil, realizada aos 12 meses após o plantio, e com o índice de área foliar (LAI) avaliado em datas diferentes. Esse índice foi estima- do utilizando o equipamento LI-COR LAI 2000 (Li-Cor Incorporated, Lincoln, NE, USA), segundo o método descrito por Welles e Norman (1991) e Lamade (1997). Foram feitas medidas aos 3; 6; 9 e 12 meses de plantio.

Os dados obtidos para cada tratamento foram submetidos à análise de variância, com comparação entre médias de tratamentos e do crescimento no tempo (meses após o plantio) realizada pelo teste de Duncan a 5\% de probabilidade. Foi aplicada análise de regressão e ajuste de equações para modelar a resposta das doses crescentes do biossólido ao acúmulo da fitomassa, com base na média dos tratamentos.

\section{RESULTADOS E DISCUSSÃO}

Na evolução do desenvolvimento da fitomassa aérea fresca da pupunheira durante os 12 meses, observou-se que o acúmulo inicial foi pequeno, sem haver diferenças entre as doses até quatro meses após a instalação do experimento (Figura 1). Diferenças estatísticas significativas entre os tratamentos começaram a ser detectadas a partir do $5^{\circ}$ mês de plantio, quando os resultados encontrados para a dose $400 \mathrm{~kg} \mathrm{~N} \mathrm{ha}^{-1}$ foram significativamente maiores (média de $0,17 \mathrm{~kg}$ planta $^{-1}$ ) que os dos demais. A taxa de acúmulo da fitomassa foi aumentando, particularmente a partir do sétimo mês, começando então a haver diferenças estatísticas entre as doses de biossólido e o tratamento testemunha. A partir dessa data houve maior acréscimo na taxa de crescimento absoluto em fitomassa, a qual perdurou até o décimo mês de plantio.

Entre o décimo e o décimo primeiro mês ocorreu déficit hídrico acentuado que causou menor taxa de crescimento das plantas nesse período. Sintomas típicos de estresse hídrico puderam ser visualizados nessa época. As chuvas ocorridas após esse período restabeleceram a reserva hídrica do solo, com conseqüente retomada do crescimento.

Observou-se que doses crescentes de biossólido aumentaram de forma representativa a fitomassa total da pupunheira ao longo do tempo, devido provavelmente à liberação gradual dos nutrientes disponíveis para as plantas (Olivei- 
ra, 2000; Vega, 2003). Não houve efeito negativo, não ocorrendo diminuição da produção de fitomassa mesmo na dosagem maior, de $152 \mathrm{t} \mathrm{ha}^{-1}$ de lodo fresco $\left(400 \mathrm{~kg} \mathrm{ha}^{-1} \mathrm{de} \mathrm{N}\right)$, correspondente a aproximadamente $32 \mathrm{t} \mathrm{ha}^{-1}$ de lodo seco na dose máxima. Efeitos fitotóxicos de doses elevadas de biossólido foram reportados para algumas culturas. Tsutiya (2001) observou em eucalipto (Eucalyptus grandis), que doses maiores que $35 \mathrm{t} \mathrm{ha}^{-1}$ de biossólido na base seca (biossólido da ETE Barueri) a partir dos 22 meses de plantio causaram decréscimo no volume cilíndrico da planta $\left(\mathrm{m}^{3} \mathrm{ha}^{-1}\right)$.

Doze meses após a aplicação de biossólido, as plantas que receberam a dose máxima tinham mais que o dobro da fitomassa aérea da testemunha $(5,04$ e 2,11 kg planta ${ }^{-1}$, respectivamente). Foi elaborada equação geral de resposta do acúmulo de fitomassa aos 12 meses em função da aplicação de doses crescentes de biossólido no plantio. A equação de melhor ajuste foi a quadrática: $y=a+b x+c x^{2}$, com valores para $\mathrm{a}=$ $2,3318, \mathrm{~b}=8,3738 \mathrm{e}^{-3} \mathrm{e} \mathrm{c}=-2,0477 \mathrm{e}^{-6}$, e alto coeficiente de determinação $\left(\mathrm{R}^{2}=\right.$ $0,96)$. O coeficiente de variação do experimento esteve entre 24,27 e $47,27 \%$ ao longo do período, valor elevado para cultivos tradicionais, mas esperado para a pupunheira devido à alta variabilidade genética, própria da espécie (Bovi et al., 1993a, 1993b).

Resultados do índice de área foliar (LAI) ao longo do tempo (Figura 2) corroboram os de fitomassa, visto que se detectou alto coeficiente de determinação $\left(\mathrm{R}^{2}=0,99\right)$ do LAI tanto com a produção da fitomassa fresca quanto com a do palmito (Vega, 2003). Observou-se que a dose maior (400 $\mathrm{kg} \mathrm{N} \mathrm{ha}^{-1}$ ) apresentou diferença estatística para a área foliar já a partir do sexto mês, terminando no $12^{\circ}$ mês com uma diferença significativa em comparação às demais $\left(2,12 \mathrm{~m}^{2}\right)$. Por sua vez, as doses 200 e 100 não diferiram entre si também aos 12 meses $\left(1,62 \mathrm{~m}^{2}\right.$ e $1,56 \mathrm{~m}^{2}$, respectivamente), mas foram estatisticamente superiores à dose $0\left(1,18 \mathrm{~m}^{2}\right)$.

As respostas da pupunheira em função de doses crescentes de biossólido não foram só em termos de área foliar e fitomassa da haste principal, mas tam-

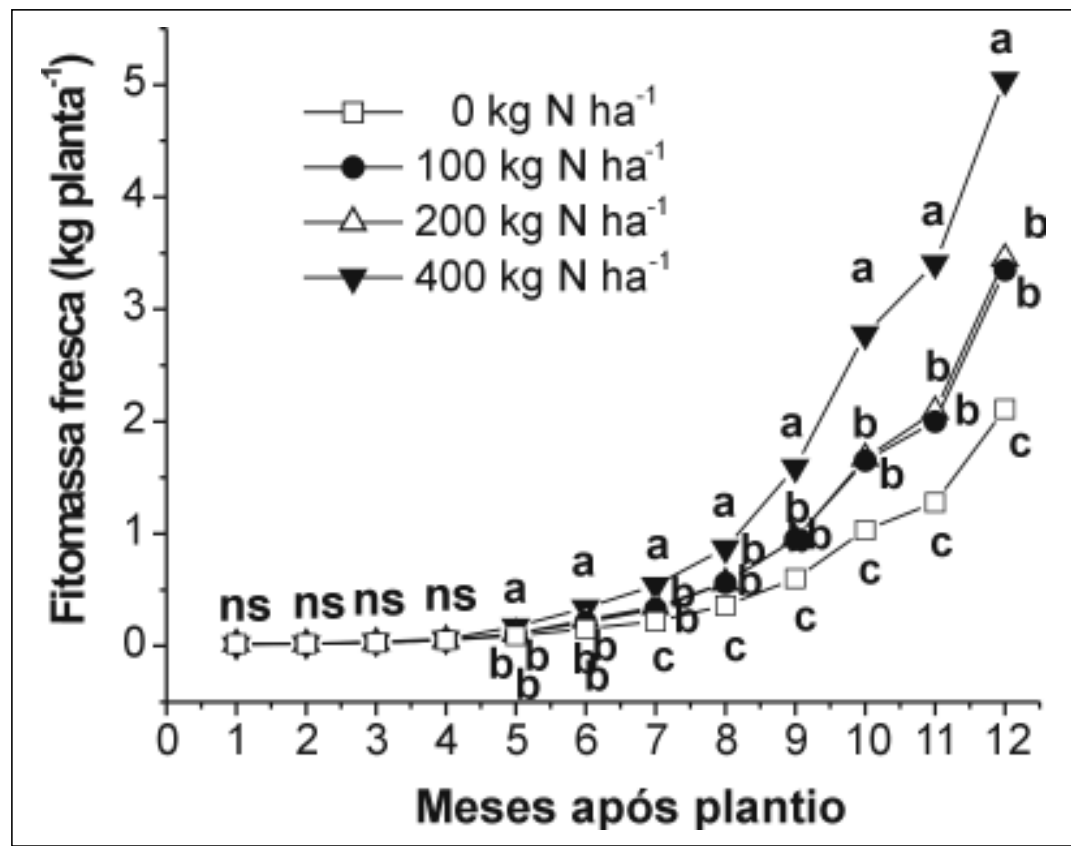

Figura 1. Fitomassa aérea fresca de pupunheira em função de diferentes doses de N. Ubatuba, IAC, 2002.

Médias seguidas da mesma letra, em cada período, não diferem entre si pelo teste de Duncan a $5 \%$. Ns = não significativo.

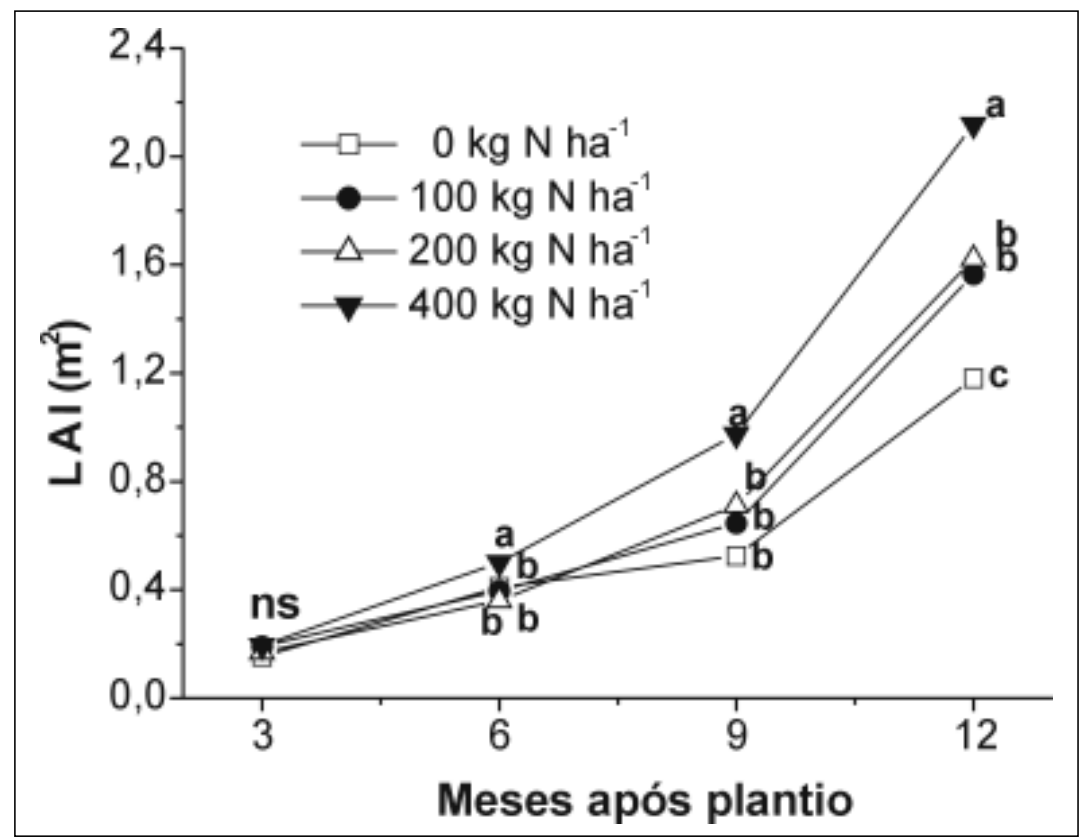

Figura 2. Índice de área foliar (LAI) de pupunheira em função de diferentes doses de N. Ubatuba, IAC, 2002.

Médias seguidas de mesma letra, em cada período, não diferem entre si pelo teste de Duncan a $5 \%$. Ns = não significativo.

bém no número médio de perfilhos por planta e na porcentagem de plantas perfilhadas por parcela. Doze meses após a aplicação do biossólido, observou-se que o número total de perfilhos na dose 400 (3,3 perfilhos por planta) 
diferiu estatisticamente da dose $0(1,7$ por planta), mas não das doses $100 \mathrm{e}$ 200. Estas foram estatisticamente iguais entre si, com 2,4 e 2,3 perfilhos por planta, respectivamente. Da mesma forma, a porcentagem de plantas perfilhadas aos doze meses chegou a $77,1 \%$ na dose 400 , enquanto as doses 200 e 100 tiveram 67,7 e $64,6 \%$ de plantas perfilhadas, respectivamente. Por sua vez a dose 0 apresentou apenas $56,3 \%$ das suas plantas perfilhadas aos 12 meses no campo. Esses valores são superiores aos encontrados por Bovi et al. (2002) com doses similares de nitrogênio aplicado periodicamente como fertilizante químico. Nesse caso, a porcentagem máxima de plantas perfilhadas foi $40 \%$, com um perfilho por planta em média, para a dose maior (400) aos 12 meses de plantio. Da mesma forma, Bovi et al. (2000) em outro experimento com progênies provenientes de Yurimaguas, e testando doses crescentes de matéria orgânica (composto de lixo), fósforo e magnésio, encontraram efeito linear positivo do acréscimo de matéria orgânica sobre esses dois caracteres, reportando $75 \%$ de plantas perfilhadas e 3,5 perfilhos por planta na dose de $40 \mathrm{t} \mathrm{ha}^{-1}$ de composto de lixo.

No cálculo da fitomassa aérea total da pupunheira submetida a doses crescentes de biossólido observou-se que, a fitomassa dos perfilhos representou, em média, de 3,6 (dose 0) a 6,4\% (dose 400) do total da fitomassa. Devido à baixa contribuição dos perfilhos, considera-se a estimativa da fitomassa da planta mãe, ou haste principal, como representativa para o cálculo da fitomassa total da touceira para esse estádio do cultivo. Há uma relação direta entre ambas, com coeficiente de determinação bastante elevado $\left(\mathrm{R}^{2}=0,99\right)$, representada pela equação linear $\mathrm{y}=0,01269+1,01997 \mathrm{x}$, onde $y$ é a fitomassa aérea total e $x$ é a fitomassa aérea apenas da haste principal.

Extrapolando os resultados para um cultivo comercial em espaçamento $2 \mathrm{x} 1$ m (5.000 plantas ha $\left.^{-1}\right)$, obtém-se um acúmulo bastante significativo de fitomassa fresca para a dose maior (400) de biossólido, ao redor de $27 \mathrm{t} \mathrm{ha}^{-1}$. Produção similar foi anteriormente reportada por Clement (1995), no Hawaii, em plantio com 1,3 anos e densidade similar à do presente estudo. No entanto, ambos resultados, são quase $50 \%$ maio- res que os obtidos por Ares et al. (2002) em diferentes solos da Costa Rica em densidades maiores que 4.200 plantas ha $^{-1}$. Nas doses 200 e 100 observou-se cerca de $18 \mathrm{t} \mathrm{ha}^{-1}$, contra apenas $11 \mathrm{t} \mathrm{ha}^{-1}$ na ausência de biossólido no sulco de plantio. Observou-se também uma média geral de $22 \%$ em massa de matéria seca com relação à massa fresca total, estimando em média $78 \%$ de umidade na planta.

A pupunheira apresentou diferença estatística a partir do $5^{\circ}$ mês de plantio para as diferentes doses, tempo em que a planta se adaptou ao campo e em que os nutrientes do biossólido começaram a ser assimilados. Houve resposta positiva no acúmulo de fitomassa aérea da pupunheira ao aumento das doses de biossólido, antecipando o tempo para a primeira colheita. A dose 400 apresentou aos 12 meses de plantio $15 \%$ de plantas aptas para o corte, sugerindo precocidade na época de início do corte de palmito, considerando que segundo a literatura, normalmente este se dá ao redor dos 18-24 meses após plantio (Villachica, 1996; Bovi, 1998; Burneo, 2000). Doses crescentes de biossólido aplicadas durante o plantio resultaram também em resposta significativa no número de perfilhos e na porcentagem de plantas perfilhadas, duas características responsáveis pela sustentabilidade do cultivo.

Conclui-se portanto, que a aplicação de biossólido no sulco de plantio supriu as exigências nutricionais da pupunheira nos primeiros doze meses, exceto para potássio e boro. A ausência de fitotoxidade nas doses maiores, a resposta quase linear da fitomassa aérea em relação às quantidades de biossólido aplicado, o aumento de perfilhamento e a antecipação do ponto de corte para palmito na dose 400 , indicam a potencialidade do uso de lodo de esgoto na implantação dessa cultura. No entanto, sugere-se estudos adicionais, visto que, junto com nutrientes essenciais ao cultivo, o biossólido apresenta também metais pesados, que podem a longo prazo entrar na cadeia alimentar.

\section{AGRADECIMENTOS}

Os autores agradecem à SABESP pelo financiamento parcial do projeto de pesquisa e à FundAg pela concessão de bolsa durante o período final de mestrado do primeiro autor.

\section{LITERATURA CITADA}

ARES, A.; BONICHE, J.; MOLINA, E.; YOST, R.S. Bactris gasipaes agroecosystem for heart-ofpalm production in Costa Rica: changes in biomass, nutrient and carbon pools with stand age and plant density. Field Crops Research, v.74, n.1, p.13-22, 2002.

BASSOI, L.H.; FLORI, J.E.; ALENCAR, C.M.; SILVA, J.A.M.; RAMOS, C.M.C. Distribuição espacial do sistema radicular da pupunheira em solos irrigados no vale do São Francisco. Engenharia Agrícola, v.19, n.2, p.163-176, 1999.

BOVI, M.L.A. Palmito pupunha informações básicas para cultivo. Campinas, IAC - Boletim Técnico 173, 1998. 50 p.

BOVI, M.L.A.; CANTARELLA, H. Pupunha para extração de palmito. In: RAIJ, B.; CANTARELLA, H.; QUAGGIO, J.A.; FURLANI, A.M.C. (Eds.). Recomendações de adubação para algumas culturas do estado de São Paulo. Campinas: Instituto Agronômico, 1996. p.240-242 (Boletim Técnico, 100).

BOVI, M.L.A.; GODOY JÚNIOR, G.; CAMARGO, S.B.; SPIERING, S.H. Caracteres indiretos na seleção de pupunheiras inermes (Bactris gasipaes H.B.K.) para palmito. In: CONGRESO INTERNACIONAL SOBRE BIOLOGIA, AGRONOMIA E INDUSTRIALIZACION DEL PIJUAYO, 4., 1993, Iquitos. Anais... San José: UFCR, 1993a. p.163-176. BOVI, M.L.A.; GODOY, JR, G.; CAMARGO, S.B.; SPIERING, S.H. Seleção precoce em pupunheiras (Bactris gasipaes H.B.K.) para produção de palmito. In: CONGRESO INTERNACIONAL SOBRE BIOLOGIA, AGRONOMIA E INDUSTRIALIZACION DEL PIJUAYO, 4. 1993, Iquitos. Anais.... San José: UFCR, 1993b. p.177-195.

BOVI, M.L.A.; GODOY, JR.G.; SPIERING, S.H Adubação de implantação afetando perfilhamento em pupunheira. In: REUNIÃO BRASILEIRA DE MANEJO E CONSERVAÇÃO DO SOLO E DA ÁGUA, 13., 2000, Ilhéus. Anais eletrônicos... Ilhéus: CEPLAC, 2000. CD-ROM.

BOVI, M.L. A; GODOY, JR.G.; SPIERING, S. H. Respostas de crescimento da pupunheira à adubação NPK. Scientia Agricola, v.59, n.1, p.161-166, 2002.

BURNEO, J. Cultivo de palmito (Bactris gasipaes Kunth): Resumen reunión estratégica división agrícola - INAEXPO, Quito, 2000, 119 p.

CLEMENT, C.R. Growth and analysis of pejibaye (Bactris gasipaes Kunth, Palmae) in Hawaii. 1995. 221 p. (Tese Doutorado), University of Hawaii, Honolulu.

CLEMENT, C.R.; BOVI M.L.A. Padronização de medidas de crescimento e produção em experimentos com pupunha para palmito. Acta Amazônica, v.30, n.3, p.349-362, 2000.

FALCÃO, N.P.S.; SILVA, J.R.A.; CLEMENT, C.R. Caracterização de sintomatologia de carências nutricionais em mudas de pupunheira (Bactris gasipaes Kunth), cultivada em solução nutritiva. In: REUNIÃO BRASILEIRA DE FERTILIDADE DO SOLO E NUTRIÇÃO DE PLANTAS, 23., 1998, Caxambu. Anais... Caxambu: SBCS 
1998. p.11-16.

JORGE, J.A.; BOVI, M.L.A.; Influência das propriedades físicas e químicas do solo no crescimento da palmeira pupunha. In: CONGRESSO BRASILEIRO DE FRUTICULTURA, 13., 1994, Salvador. Anais... Salvador: SBF, 1994. p.1145-1146. LAMADE, E. Métode rapide de mesure de l'indice foliaire du palmier é huile. Plantation, recherché, développement, v.4, n.6, p.385-391, 1997.

MELO, W.J.; MARQUES, M.O. Potencial do lodo de esgoto como fonte de nutrientes para as plantas. In: BETTIOL E CAMARGO (Eds.) Impacto ambiental do uso agrícola de lodo de esgoto. Jaguariúna: Embrapa Meio Ambiente, 2000. p.109-141.

OLIVEIRA, F.C. Disposição de lodo de esgoto e composto de lixo urbano num Latossolo Vermelho-Amarelo cultivado com cana-de-açúcar. 2000, 247 p. (Tese doutorado), ESALQ, USP,
Piracicaba.

RAMOS, A. Análise do desenvolvimento vegetativo e produtividade da palmeira pupunha (Bactris gasipaes Kunth) sob niveis de irrigação e adubação nitrogenada. 2002, 113 p. (Tese doutorado), ESALQ, USP, Piracicaba.

RAMOS, A ; BOVI, M.L.A ; FOLEGATTI, M.V.

Desenvolvimento vegetativo da pupunheira irrigada por gotejamento em função de níveis de depleção de água no solo. Horticultura Brasileira, Brasília, v.20, n.1, p.28-33, 2002.

SCHROTH, G.; ELIAS, M.E.A.; MACÊDO, J.L.V.; MOTA, M.S.S.; LIEBEREI, R. Mineral nutrition of peach palm (Bactris gasipaes) in Amazonian agroforestry and recommendations for foliar analysis. European Journal of Agronomy, v.17, n.2, p.81-92, 2002

SILVA, F.C.; BOARETTO, A.E.; BERTON, R.S.; ZOTELLI, H.B.; PEIXE, C.A.; MENDONCA, E. Cana-de-açúcar cultivada em solo adubado com lodo de esgoto: nutrientes, metais pesados e produtividade. Pesquisa Agropecuária Brasileira,
Brasília, v.33, n.1, p.1-8, 1998 .

TSUTIYA, M.T. Alternativas de disposição final de biossolidos. In: TSUTIYA, M.T.; CAMPARINI, J.B.; ALEM SOBRINHO, P.; HESPANHOL, I.; DE CARVALHO, P.C.T.; MELFI, A.J.; MELO, W.J.; MARQUES, M.O (Eds.) Biossolidos na agricultura. 2001. cap.5, p.133-180.

VEGA, F.V.A. Uso de lodo de esgoto na implantação da cultura da pupunheira (Bactris gasipaes Kunth). 2003. 126 p. (Tese Mestrado), IAC, Campinas.

VILLACHICA, L.M. Cultivo del pijuayo (Bactris gasipaes Kunth) para palmito en la Amazonia. Tratado de Cooperación Amazónica, Lima, 1996. $146 \mathrm{p}$.

WELLES, J.M.; NORMAN, J.M. Instrument for indirect measurement of canopy arquitecture. Agronomy Journal, v.83, n.4, p.818-825, 1991. 